\title{
Evidence-Based Treatments for Adults with Migraine
}

\author{
Rubesh Gooriah, Randa Nimeri, and Fayyaz Ahmed \\ Department of Neurology, Hull Royal Infirmary, Hull, UK \\ Correspondence should be addressed to Rubesh Gooriah; rubesh@doctors.org.uk
}

Received 17 October 2015; Accepted 9 December 2015

Academic Editor: Hartmut Göbel

Copyright (C) 2015 Rubesh Gooriah et al. This is an open access article distributed under the Creative Commons Attribution License, which permits unrestricted use, distribution, and reproduction in any medium, provided the original work is properly cited.

\begin{abstract}
Migraine, a significantly disabling condition, is treated with acute and preventive medications. However, some individuals are refractory to standard treatments. Although there is a host of alternative management options available, these are not always backed by strong evidence. In fact, most of the drugs used in migraine were initially designed for other purposes. Whilst effective, the benefits from these medications are modest, reflecting the need for newer and migraine-specific therapeutic agents. In recent years, we have witnessed the emergence of novel treatments, of which noninvasive neuromodulation appears to be the most attractive given its ease of use and excellent tolerability profile. This paper reviews the evidence behind the available treatments for migraine.
\end{abstract}

\section{Introduction}

Migraine has a lifetime prevalence of around $15 \%$ of the population, affecting women (18\%) more than men (8\%) [1]. It has been termed the seventh disabler due to its considerable impact on the quality of life (QOL) of patients [2]. A subset of patients progresses from having episodic migraine (EM) to chronic migraine (CM), the latter affecting $1 \%-2 \%$ of the population [3]. This is a gradual process, initially changing from low-frequency EM to a high-frequency stage and eventually to CM [4]. CM is defined as a headache on $\geq 15$ days per month for $\geq 3$ months, of which $\geq 8$ days meets the criteria for migraine with or without aura or responds to migraine-specific treatment [5]. Migraines have significant psychological, social, and economic impacts [6]. Around $75 \%$ of patients experience impaired functioning during an attack and around half of them require help from others [6]. In addition to direct healthcare costs, the disorder results in loss of 20 million working days in England [6]. The economic annual impact of migraines is considerable and has been estimated at $€ 27$ billion in European countries [7]. The indirect costs of migraine exceed the direct costs [8] and therefore reducing the burden of this disabling condition should be an obvious healthcare intervention target. The management of migraine relies on adequate and prompt alleviation of the pain and on the reduction or complete abolition of the attacks. Several acute and prophylactic treatments are indicated for the treatment of migraines.
However, a small proportion of patients suffer from intractable migraines, whereby their attacks are inadequately controlled despite having tried a range of medications. It is interesting to note that, of the available pharmacological prophylactic treatments, none have been designed specifically for this purpose. Migraine is therefore a major public health problem which is not always effectively managed, indicating the need for additional migraine-specific drugs. This paper will review the evidence supporting the pharmacological options together with less commonly used invasive and noninvasive treatments.

\section{Pathophysiology of Migraine}

Migraine is a complex condition with an incompletely understood pathophysiology. The early "vascular theory" popularised the notion that the migraine aura was due to hypoxemia secondary to vasoconstriction and that the headache was the result of rebound vasodilatation [9]. However, when it was found that reduced blood flow was still present at the onset of headaches, it became evident that the vascular theory could not account for all the features of migraine with aura [10]. The alternative and widely accepted theory suggests that cortical spreading depression (CSD), a wave a neuronal hyperactivity followed by an area of cortical depression, accounts for the aura $[11,12]$ and that the headache depends on activation of the trigeminovascular pain pathway [13, 14]. This has been studied in animal models leading to an 
in-depth knowledge of ionic, neurochemical, and cellular mechanisms [15]. Induction of spreading depression has been shown to cause vasodilation in meningeal vessels by a reflex dependent on trigeminal and parasympathetic pathways [16]. An array of messengers, including substance $P$ and calcitonin gene-related peptide (CGRP) [17], activate or sensitize painsignalling pathways in relation to CSD in animal models [15]. CSD has also been reported to cause changes in brainstem nociceptive neuronal activity even when the trigeminal pathway has been inhibited [18]. In humans, functional imaging has shown changes in cortical function and blood flow and the patterns of spread are suggestive of CSD [15].

In $\mathrm{CM}$, atypical pain processing, central and peripheral sensitization, cortical hyperexcitability, and neurogenic inflammation all have a role to play [19]. Central sensitization refers to a state in which nociceptive neurons in the spinal and medullary dorsal horn exhibit increased excitability, increased synaptic strength, and enlargement of their receptive fields beyond the original site of inflammation or injury [20]. Peripheral sensitization defines a state in which primary afferent nociceptive neurons display enhanced responsiveness to external mechanical or thermal stimuli at the site of inflammation or injury. Peripheral sensitization of the trigeminal nerve, and the blood vessels supplied by them, accounts for the throbbing pain. This stage of migraine is termed first-order neuron sensitization [21]. Second-order neuron sensitization occurs when sensitization spreads to the second-order trigeminovascular neurons in the spinal trigeminal nucleus, causing scalp hypersensitivity or cutaneous allodynia [21]. Third-order sensitization is the result of sensitization spreading to the thalamus, which causes extracephalic hypersensitivity [21]. Allodynia is therefore the clinical manifestation of second- and third-order neuron sensitization and a marker of migraine progression [22]. There is evidence that allodynia symptoms occur more commonly in patients who have an extensive history of CM [22]. Migraines are mostly nonallodynic initially but become allodynic after a few years with repeated attacks due to sensitization of the trigeminovascular pathway, which results in a lower threshold for activation and therefore more frequent migraine attacks. This makes allodynia a marker of chronification [23]. Cortical hyperexcitability is thought to be another major factor participating in transformation of EM to CM [24]. Increased cortical excitability, compared to subjects with EM and migraine-free controls, has been shown in subjects with CM $[25,26]$. Aurora et al. [27] demonstrated that magnetic suppression of perceptual accuracy was significantly reduced in 25 patients with CM compared with subjects with EM and migraine-free controls, indicating increased cortical excitability. Positron emission tomography scan studies were also performed in ten of the patients with CM, and an enhanced metabolism was observed in the pons and right temporal cortex compared to global cerebral metabolism.

\section{Acute Treatment}

The acute management of migraine attacks aims at achieving rapid pain relief. Several drugs have been shown to be effective in placebo-controlled trials. In many patients, simple analgesics are usually sufficient for controlling pain during an attack. However, some individuals have a suboptimal response to analgesics and can be offered other medications such as $5-\mathrm{HT1B} / 1 \mathrm{D}$ receptor agonists, which are migrainespecific. Opiates should be avoided as far as possible for the treatment of acute migraines.

3.1. Analgesics. Analgesics are the drugs of first choice for migraines of mild or moderate severity. Aspirin [28, 29], paracetamol [30], ibuprofen [31], naproxen [32], diclofenac [33], phenazone [34], and tolfenamic acid [35] have all demonstrated efficacy in placebo-controlled trials. Paracetamol has the advantage of causing less gastric irritation. Ibuprofen is probably the most widely used nonsteroidal antiinflammatory drug (NSAID) and, while is at least as effective as aspirin, it may also cause less gastric side effects. Diclofenac has a rapid onset of action whilst naproxen, which has a longer half-life, has a slower onset of action. Effervescent acetylsalicylic acid has a faster onset of action (depending on the formulation) than regular tablets and has shown efficacy similar to that of sumatriptan $50 \mathrm{mg}$. In addition, the combination of aspirin, paracetamol, and caffeine is more effective than either drug taken alone or in combination without caffeine [36-38]. Valdecoxib, a COX-2 inhibitor, has been shown to be effective for acute migraine treatment [39]. These analgesics should be taken as soon as the headache starts. The concomitant use of an antiemetic is recommended to treat nausea [40]; also antiemetics are believed to improve the absorption of analgesics [41-43]. There is no evidence, however, that the combined use of an antiemetic with an analgesic is more effective than the analgesic alone. To avoid medication overuse headache $(\mathrm{MOH})$, patients should use these analgesics as infrequently as possible and on less than 15 days per month.

3.2. 5-HT1B/1D Receptor Agonists (Triptans). The so-called "triptans" are considered to be the gold standard symptomatic treatment. They are considered as a second line when patients have inadequate response to simple analgesics. Seven triptans, all of which have strong evidence of efficacy, are marketed, namely, sumatriptan, zolmitriptan, naratriptan, rizatriptan, almotriptan, eletriptan, and frovatriptan. They are thought to act via three potential mechanisms: cranial vasoconstriction [44], peripheral neuronal inhibition [45], and inhibition of transmission through second-order neurons of the trigeminocervical complex [46]. However, they differ in terms of their pharmacodynamics and pharmacokinetic properties and are therefore expected to exhibit differences regarding their efficacy and tolerability profile. With the exception of naratriptan, the oral triptans provide headache relief within 30 to 60 minutes. Response rates at 2 hours range from $50 \%$ to $80 \%$, with $20 \%$ to $50 \%$ of patients being painfree [47, 48]. A meta-analysis of 53 trials [49] showed that eletriptan $80 \mathrm{mg}$ and rizatriptan $20 \mathrm{mg}$ have higher 2-hour response rates than sumatriptan $100 \mathrm{mg}$ and that naratriptan $2.5 \mathrm{mg}$ and frovatriptan $2.5 \mathrm{mg}$ have the lowest response rates. Eletriptan has the lowest recurrence rates at 2 hours [49]. If oral intake exacerbates nausea, the use of dissolving tablets 
(wafers) of rizatriptan $10 \mathrm{mg}$ and zolmitriptan $2.5 \mathrm{mg}$ can be considered. Parenteral formulations can also be useful in patients with nausea or vomiting. Subcutaneous sumatriptan appears to have the best clinical efficacy with a $76 \%$ response rate [50]. Sumatriptan and zolmitriptan are also available in the form of nasal sprays. However, the dysgeusia associated with nasal spray can worsen nausea. The tolerability profile of rizatriptan, sumatriptan, zolmitriptan, and eletriptan appears to be largely similar [51]. Triptans are associated with medication overuse headaches, but the withdrawal is shorter in duration and less in severity than other patients using ergots and other analgesics [52]. Contraindications for the use of triptans are untreated arterial hypertension, coronary heart disease, Raynaud's disease, history of ischaemic stroke, pregnancy, lactation, and severe liver or renal failure [40]. Triptans should not be taken on less than 10 days per month to avoid the emergence of $\mathrm{MOH}$.

3.3. Ergot Derivatives. Placebo-controlled trials addressing the efficacy of ergot derivatives are scarce, although experience with their use is not lacking, having been available for many years. Data from comparative trials have shown ergot derivatives to be inferior to triptans $[53,54]$. Ergotamine tartrate and dihydroergotamine (DHE) are the only two compounds with sufficient evidence of efficacy. Some patients who have an inadequate response to triptans will benefit from DHE, the preferred ergot derivative. It is available as a nasal spray and can also be injected subcutaneously or intramuscularly. The main side effects include nausea, vomiting, paraesthesia, and ergotism. It is contraindicated in cardiovascular and cerebrovascular diseases, Raynaud's disease, arterial hypertension, renal failure, and pregnancy and lactation.

\section{Preventive Treatment}

4.1. Oral Pharmacotherapy. The aims of migraine prophylaxis are to reduce migraine frequency, severity, and disability and improve quality of life. The overuse of analgesic medications can lead to the development of chronic migraine. Therefore preventive medications also serve to limit the need for frequent analgesic intake, thereby reducing the risk of migraine chronification.

4.1.1. Topiramate. Topiramate has numerous modes of action that include inhibition of glutamatergic excitatory amino acid transmission, inhibition of voltage-gated calcium channels, enhancement of GABA-evoked currents, fast $\mathrm{Na}+$ channel blockade, and carbonic anhydrase inhibition [55]. It is thought to act on processes that suppress the initiation and propagation of CSD [56]. Its benefits in the prophylaxis of migraine were initially shown in two relatively small randomised placebo-controlled trials $[57,58]$. In a multicenter randomised double-blind, placebo-controlled study of 468 patients meeting the IHS criteria for episodic migraine, Brandes et al. [59] found that topiramate at doses of $100 \mathrm{mg} /$ day and $200 \mathrm{mg} /$ day significantly reduced the mean monthly migraine frequency compared to placebo $(-2.1$, $p=0.008$ and $-2.4, p<0.001$, resp.). Silberstein et al.
[60] randomised 487 patients to placebo $(n=117)$ or topiramate $50 \mathrm{mg} /$ day $(n=125), 100 \mathrm{mg} /$ day $(n=128)$, or $200 \mathrm{mg} /$ day $(n=117)$. The study is likely to have included patients with both episodic and chronic migraines based on the frequency of the attacks. The primary efficacy end-point was a reduction in mean migraine frequency from baseline. Secondary efficacy end points included time to onset of action, proportion of subjects responding to treatment $(\geq 50 \%$ reduction in the monthly migraine frequency), mean change in monthly migraine days, and change in number of days per month requiring rescue medication from the end of the prospective baseline phase through the double-blind phase. During the 6-month period, 158 patients withdrew, $83(52.5 \%)$ of which were due to adverse events. Topiramate was associated with a dose-dependent significant decrease in mean monthly migraine frequency from baseline, with a mean reduction of 2.3 days seen with a dose of $200 \mathrm{mg} /$ day, confirming the results from Brandes et al. [59]. The most common AEs observed were paraesthesia, fatigue, anorexia, taste perversion, and nausea. These events seemed to be dose dependent and generally resolved over time or with discontinuation. Topiramate is approved for the prevention of EM by the Food and Drug Administration (FDA) and is recommended by the National Institute for Health and Care Excellence (NICE) guidelines [61], but its use is mainly hampered by its side effect profile.

Topiramate is also effective in the prevention of CM. Its efficacy was initially shown in a small randomised, doubleblind, placebo-controlled trial with 28 patients suffering from chronic migraine with overuse of acute medications [62]. Diener et al. [63] included 59 patients with CM (32 patients receiving topiramate and 27 receiving placebo) as defined by the ICHD-2 criteria [64] in a randomised, doubleblind, placebo-controlled trial. The primary efficacy variable was the change in the mean number of monthly migraine days from baseline to the last 4 weeks of the double-blind phase. Topiramate intake resulted in a significant decrease in the mean number of monthly migraine days from $15.5 \pm$ 4.6 at baseline by $3.5 \pm 6.3$ in the last 4 weeks of the double-blind phase, compared with an increase of $0.2 \pm$ 4.7 days from $16.4 \pm 4.4$ at baseline for patients receiving placebo $(p=0.02)$. A larger study was needed to confirm this. In a randomised, double-blind, placebo-controlled trial involving 306 patients (topiramate, $n=153$; placebo, $n=$ 153) and consisting of 16 weeks of double-blind treatment, topiramate (titrated to a maximum dose of $100 \mathrm{mg} /$ day) resulted in a statistically significant mean reduction of migraine/migrainous headache days (topiramate -6.4 versus placebo $-4.7, p=0.010)$ and migraine headache days relative to baseline (topiramate -5.6 versus placebo $-4.1, p=0.032$ ) compared to placebo [65]. Adverse events were reported in $80.2 \%$ of the topiramate-treated group compared to $70.2 \%$ in the placebo-treated group leading to discontinuations in $18(10.9 \%)$ topiramate subjects and $10(6.1 \%)$ placebo subjects.

4.1.2. Amitriptyline. There are a few old placebo-controlled trials supporting the use of amitriptyline for migraine prophylaxis, but they are small $[66,67]$. The evidence that best 
supports the use of amitriptyline for migraine prophylaxis emanates from a 26-week, multicenter, randomised, doubleblind, double-dummy, parallel-group, noninferiority study comparing it to topiramate [68]. The intent-to-treat population included 331 subjects (172 topiramate, 159 amitriptyline). The primary efficacy outcome was the change from prospective baseline in the mean monthly number of migraine episodes. There was no significant difference between the groups in the least squares mean (LSM) change from baseline in the mean monthly number of migraine episodes $(-2.6$ and -2.7 , resp.). However, topiramate conferred a significantly greater improvement in mean functional disability scores during migraine attacks compared with amitriptyline (LSM change: -0.33 versus $-0.19 ; 95 \% \mathrm{CI},-0.3$ to $0.0 ; p=0.040$ ) and in the function-restrictive role, function-preventive role, and emotional function domains of the MSQ $(p=0.012$, $p=0.014$, and $p=0.029$, resp.). A mean weight loss of $2.4 \mathrm{~kg}$ was observed in subjects receiving topiramate, compared with a mean weight gain of $2.4 \mathrm{~kg}$ in subjects receiving amitriptyline. Adverse events were reported in $66.7 \%$ and $66.3 \%$ of those on topiramate and amitriptyline, respectively.

4.1.3. Beta-Blockers. The benefits of beta-blockers in migraine prevention were noted fortuitously in those who were being treated for hypertension. Propranolol and metoprolol have the best evidence in migraine prophylaxis. Several trials show clear and consistent evidence that propranolol is more effective than placebo, although the majority of these have methodological weaknesses. Its efficacy is nonetheless considered to be well established and has been supported by a Cochrane review [69]. When compared to amitriptyline, propranolol has been found to have a similar efficacy [70]. Most of the trials used the conventional formulation of propranolol. Pradalier et al. [71] showed that the long-acting preparation of propranolol was also effective in reducing the frequency of migraine attacks. Studies with propranolol reported efficacy with doses of 80 to $240 \mathrm{mg}$, with both conventional and slowrelease formulations. Metoprolol has been found to exert a prophylactic effect comparable to that of propranolol [7274]. With regard to other beta-blockers, the evidence is less convincing. Timolol [75] and nadolol [76] have both been found to be equally effective to propranolol. Bisoprolol, a highly selective beta-1 adrenoceptor antagonist, has a similar efficacy to metoprolol [77] while atenolol has been shown to be superior to placebo [78]. Side effects of beta-blockers include fatigue, hypotension, bradycardia, depression, and vivid dreams. They are contraindicated in asthmatics.

4.1.4. Valproic Acid. Valproic acid is thought to block neurogenic inflammation within the meninges through $\mathrm{GABA}_{\mathrm{A}^{-}}$ mediated receptors [79]. Hering and Kuritzky [80] reported the first double-blind placebo-controlled trial of sodium valproate in migraine prophylaxis. Further randomised placebocontrolled trials using valproic acid (sodium valproate or divalproex sodium) provided additional evidence of its efficacy in migraine prophylaxis [81-83]. Valproic acid has been found to be equally effective to propranolol in a singleinvestigator, randomised, single-blind, placebo-controlled study [84]. Of the 37 patients recruited, 32 completed the study. Migraine frequency was reduced in $19 \%(6 / 32)$ of placebo-treated, 66\% (21/32) of divalproex-treated, and 63\% (20/32) of propranolol-treated patients [84]. When compared to flunarizine, valproic acid was also found to have similar efficacy [85]. Freitag et al. [83] found no significant differences between treatment groups either in the overall incidence or in the incidence of any specific treatment-emergent adverse event; $8 \%$ of subjects treated with extended-release divalproex sodium and $9 \%$ of those treated with placebo discontinued for adverse events [83]. A Cochrane review published in 2013 concluded that valproic acid was effective and well-tolerated in adults with episodic migraine [86]. However, given the teratogenic properties of valproate, it is not recommended in female migraineurs of child-bearing age.

4.1.5. Calcium-Channel Antagonists. Of the calcium-channel antagonists, flunarizine has the best evidence, albeit not Class I, to support its use in migraine prophylaxis. A few placebo-controlled trials are available, but these are small [87-89]. Louis [87] initially reported a statistically significant reduction in migraine attacks with flunarizine compared to placebo among 53 migraineurs. In another double-blind placebo-controlled trial involving 101 patients (flunarizine $=$ 50 , placebo $=51)$, the mean reduction in monthly migraine attacks was 2.3 in the flunarizine and 1.7 in the placebo groups $(p=0.018)$ [88]. Moreover, a phase-IV double-blind equivalence trial completed by 666 patients and designed to assess the efficacy and tolerability of two doses of flunarizine (5 mg and $10 \mathrm{mg}$ o.d.) in the prophylaxis of migraine, in comparison with slow-release propranolol (160 mg o.d.), showed that flunarizine at a dose of $10 \mathrm{mg} /$ day was at least as effective as $160 \mathrm{mg}$ propranolol for primary efficacy parameters such as reduction in mean monthly attack frequency and number of responders [90]. An earlier study involving 488 patients comparing flunarizine and propranolol had shown similar results [91]. The most common side effect of flunarizine is weight gain, with one trial reporting an average gain of $0.6 \mathrm{~kg}$ [92]. Unfortunately, flunarizine is not marketed or licensed in the UK, but it is available on a named patient basis from a few centres. Cyclandelate has also been studied but with conflicting results and with the better designed studies being negative [93-97]. The evidence for cinnarizine [98100] and nimodipine [101-103] is weak, emerging mainly from small placebo controlled, comparative, or open-label studies.

4.1.6. Other Medications. Other antiepileptic drugs, such as gabapentin [104], lamotrigine [105], and oxcarbazepine [106], either are ineffective or lack robust evidence for recommendation as a migraine prophylaxis. Of the angiotensin converting enzyme inhibitors and angiotensin receptor antagonists, candesartan and lisinopril have some evidence in migraine prophylaxis. Candesartan was found to be superior to placebo in reducing secondary endpoint variables such as migraine days, headache severity, and level of disability, in a Class 
II crossover study involving 57 patients [107]. At a dose of $16 \mathrm{mg}$ per day, candesartan was shown to have similar efficacy to propranolol $160 \mathrm{mg} /$ day in a relatively large comparative study [108]. Lisinopril is supported by a relatively small double-blind placebo-controlled trial showing a statistically significant reduction in the number of headache and migraine days and in headache severity [109]. With regard to antidepressants, whilst amitriptyline has good evidence to support its use, fluoxetine has revealed conflicting results. It was shown to be effective in a small placebo-controlled trial [110], but these results were not replicated in a larger trial [111]. Venlafaxine has been shown to be effective in a randomised, double-blind, placebo-controlled study involving 60 patients with migraine. Extended-release venlafaxine at a dose of $150 \mathrm{mg} /$ day was more effective than $75 \mathrm{mg} /$ day or placebo in reducing the number of headache attacks [112]. A Class II trial assessed the efficacy of venlafaxine versus amitriptyline. Both were effective in reducing the frequency of attacks (venlafaxine: baseline $=4.15(\mathrm{SD} \pm 2.24)$ versus 12 weeks $=1.77$ (SD $\pm 1.39 ; p<0.001)$; amitriptyline: baseline $=$ $3.27(\mathrm{SD} \pm 1.61)$ versus 12 weeks $1.54(\mathrm{SD} \pm 1.54 ; p<$ $0.001)$ ) [113]. The serotonin blocker pizotifen (pizotyline) has been evaluated in several placebo-controlled and comparison trials, showing consistent efficacy for migraine prevention [114-118]. However, in the majority of these trials, it was poorly tolerated causing weight gain and sedation and was associated with a high incidence of withdrawals due to adverse events. These have limited its use. Pizotifen is not available in the United States. A technical review of clonidine including 16 trials found that it lacked conclusive evidence of efficacy [119]. Three of the eleven placebo-controlled trials showed a statistically significant improvement over placebo, but the magnitude of this was small [119]. When clonidine was compared to propranolol [120,121], these trials have yielded mixed results. Herbal remedies, vitamins, and other supplements also have some role in migraine prophylaxis. The root extract of butterbur (Petasites hybridus) has been shown to be safe [122] and effective in placebo-controlled trials $[123,124]$. A Cochrane systematic review and metaanalysis of studies investigating the effectiveness of feverfew was negative, therefore restricting its use [125]. The evidence supporting the use of riboflavin is scarce, with one placebocontrolled trial showing that a daily dose of riboflavin $400 \mathrm{mg}$ was superior to placebo [126]. Magnesium has been evaluated in 2 placebo-controlled trials for migraine prevention [127, 128] and one assessing its efficacy in menstrual migraine [129]. The first two trials showed benefit over placebo, while the third one failed to show any significant difference. It is worth noting that these three studies measured different endpoints.

\subsection{Needle Interventions/Injections}

4.2.1. Onabotulinumtoxin A. Onabotulinumtoxin A is approved for the treatment of numerous disorders [130]. Its serendipitous benefits as a prophylactic treatment for migraine were observed when it was used as a cosmetic treatment for wrinkles [131]. Freitag et al. [132] carried out a randomised, double-blind, placebo-controlled trial studying onabotulinumtoxin A for CM. Sixty patients were randomised and $100 \mathrm{U}$ of onabotulinumtoxin $\mathrm{A}$ was administered in a fixed dose and site paradigm. It was shown to be significantly superior to placebo for the primary end point of reduction in migraine headache episodes. Larger and more robust trials were still needed to confirm these findings, and they came in the form of the Phase III REsearch Evaluating Migraine Prophylaxis Therapy (PREEMPT) trials $[133,134]$. These were multicenter, double-blind, placebo-controlled studies conducted to evaluate the efficacy and safety of onaBoNTA for the prophylaxis of headaches in patients with CM. PREEMPT 1 failed to achieve its primary efficacy end-point which was the mean change from baseline in frequency of headache episodes for the 28-day period ending with week 24 . With regard to secondary efficacy end points, there was a significant between-group difference in the mean decrease from baseline in the frequency of headache days observed at all time points $(-7.8$ onaBoNTA versus -6.4 placebo, $p=0.006$ ). PREEMPT 2 was methodologically similar to PREEMPT 1 , except that the primary efficacy end point of PREEMPT 2 was switched to a mean change from baseline in the frequency of headache days instead of headache episodes. Both PREEMPT studies showed a similar mean change from baseline in frequency of headache episodes in the onaBoNTA group $(-5.2$ and -5.3 , resp.). A pooled analysis $(n=1,384)$ showed a statistically significant mean reduction from baseline in the frequency of headache days favouring onaBoNTA over placebo at week 24 ( -8.4 versus $-6.6 ; p=0.01)$ and all other time points [135]. More importantly, relevant improvements in functioning and health-related quality of life were observed with onaBoNTA compared with placebo in both trials. These improvements were even more manifest in the pooled analyses. The PREEMPT trials have been criticised for the high placebo effect observed, for enrolling a majority of patients with concomitant medication overuse, and for the fact that only $40 \%$ of its subjects had previously received a migraine prophylactic [136]. They have nevertheless established the efficacy, safety, and tolerability of onabotulinumtoxin A for CM.

4.2.2. Greater Occipital Nerve Block (GONB). Peripheral nerve blocks have been practised over the past few years for different forms of headaches. The greater occipital nerve has sensory fibres originating mainly form the $\mathrm{C} 2$ segment of the spinal cord [137]. The rationale for using GONB relies on the functional and anatomical continuum between nociceptive trigeminal and upper cervical afferents. Several techniques to perform occipital nerve blocks exist, all of which seem to be effective [138]. However, controlled trials assessing its therapeutic benefits in migraines are lacking, most of them being small and uncontrolled [139, 140]. A study of 97 patients with migraine and 87 with posttraumatic headache who had GONB with a combination of lidocaine and methylprednisolone showed a significant improvement in $54 \%$ of migraineurs for up to 6 months [140]. The presence of occipital tenderness increases the likelihood of a positive response. Over the past few years, there has been renewed interest in GONB. However, despite the fact that 
it is generally safe, potential side effects, such as dizziness, light-headedness and nausea, and rarely cardiac arrhythmias and hypersensitivity reactions, relimit its use [138]. Also, the invasive nature of the procedure makes it less acceptable to patients as a first-line treatment. We nevertheless use GONB effectively in a subset of patients who are refractory to conventional pharmacotherapy.

4.2.3. Acupuncture. Acupuncture, which refers to the application of needles to specific body parts, is widely used in healthcare systems of countries in the East and is well received by the general public. However, despite being introduced as far back as the 17th century in Europe, it is still met with scepticism about its efficacy. Acupuncture has been found to be effective in an array of medical conditions. Several trials have investigated the efficacy of acupuncture for migraine prevention [141-143], and, in recent years, larger and more robust trials have been undertaken [144-147]. The results have been mixed especially when true acupuncture has been compared to sham acupuncture. When acupuncture has been compared with metoprolol, Streng et al. [148] found that the number of migraine days decreased by an average of 2.5 days in the acupuncture group versus 2.2 days in the metoprolol group and that the proportion of responders (reduction of migraine attacks by $>$ or $=50 \%$ ) was $61 \%$ for acupuncture and $49 \%$ for metoprolol, although these did not reach statistical significance. This small difference could be explained by the larger placebo effects that accompany physical interventions [149]. Linde et al. [150] felt that sham acupuncture might be associated with larger effects than pharmacological and other "physical placebos" after reanalysing data published in a Cochrane review. Interestingly, Diener et al. [146] randomised 960 patients to verum acupuncture $(n=313)$, sham acupuncture $(n=339)$, or standard therapy $(n=$ 308 ) and found mean reduction of 2.3 days (95\% CI 1.9$2.7)$ in the verum acupuncture group, 1.5 days (1.1-2.0) in the sham acupuncture group, and 2.1 days (1.5-2.7) in the standard therapy group at 26 weeks, but this was not statistically significant across treatment groups. The proportion of responders, defined as patients with a reduction of migraine days by at least $50 \%$, was $47 \%$ in the verum group, $39 \%$ in the sham acupuncture group, and $40 \%$ in the standard group $(p=0.133)$. This again supports the possibility that sham acupuncture achieves more than pharmacological placebo and raises the question of whether sham acupuncture differs significantly from verum acupuncture. A systematic review of clinical trials between 2005 and 2006 revealed that most studies failed to show a statistically significant difference in outcomes, and most of these $(13 / 22=59 \%)$ found that sham acupuncture may be as efficacious as true acupuncture [151]. This review casts doubts on the importance of accurate needle placement of specific body points during acupuncture. This was acknowledged by a Cochrane review which also concluded that acupuncture is at least as effective as, or possibly more effective than, prophylactic drug treatment and has fewer adverse effects [152].

4.3. Neuromodulation. Neuromodulation influences pain signals for the purpose of reversible modification of the nociceptive system function by the exogenous application of electrical currents [153].

4.3.1. Transcranial Magnetic Stimulation. Transcranial magnetic stimulation (TMS) is thought to disrupt CSD by delivering a fluctuating magnetic field from the scalp by which small electrical currents are induced in the brain [154]. There is robust evidence to suggest that single-pulse TMS (sTMS) is effective as an acute treatment for migraine with aura. In a randomised, sham-controlled involving 42 patients, there was a significantly higher pain relief or painfree rate in the sTMS treated group (69\% versus 48\%) [155]. A larger randomised, sham-controlled trial involving 164 patients assigned to either sTMS or sham stimulation in a $1: 1$ revealed significantly higher pain-free response rates after $2 \mathrm{~h}$ with sTMS $(32 / 82(39 \%))$ than with sham stimulation $(18 / 82$ $(22 \%))(p=0.0179)[156]$.

Given that sTMS is effective at treating acute migraine, one can hypothesize that repetitive TMS (rTMS) is beneficial in migraine prevention. Indeed, there is encouraging data to support rTMS for migraine prevention. After the efficacy of high-frequency rTMS was initially demonstrated in a small sham-controlled pilot study [157], Teepker et al. [158] showed a reduction of headache frequency in a study of low-frequency rTMS in 27 patients, but the difference was not significant compared to the sham-treated group. In a randomised, double-blind, placebo-controlled trial, 50 adult migraine sufferers having more than 4 attacks in a month were allocated to either high-frequency rTMS or sham treatment [159]. At 1 month, the rTMS-treated group showed a reduction in headache frequency in $78.7 \%$ compared to $33.3 \%$ in those receiving sham. Data acquired through years of use of TMS suggest that it is safe. Seizure is rare in patients who use sTMS and is the only adverse event experienced with rTMS to be concerned about, but again the risk is very low [160]. Due to its interaction with some metals, it should be avoided in patients with ferromagnetic implants. The device is chip-activated by a SIM card similar to what is used in mobile phones [161]. The consumer pays for the SIM card while the device remains the property of the manufacturer. The treatment is costly and although it is recommended by NICE, it is yet to be funded in the public sector in the UK. The main disadvantage of TMS is the size of the device, although one can only expect it to shrink with time.

4.3.2. Occipital Nerve Stimulation. Percutaneous occipital nerve stimulation (ONS) is an invasive procedure which was initially investigated in the treatment of chronic cluster headache [162]. Peripheral neurostimulation was found to be effective in an uncontrolled consecutive case series of 25 refractory patients with transformed migraine implanted with C1 through C3 peripheral nerve stimulation [163]. Matharu et al. [164] also reported 8 patients with CM who had a marked improvement with bilateral implanted occipital nerve stimulators. In a prospective, multicenter, blinded, and placebo-controlled study (ONSTIM study), Saper et al. [165] randomised 68 subjects with medically intractable CM to 
one of three treatment groups - adjustable stimulation (AS), preset stimulation (PS), and medical management (MM)using a ratio of $2: 1: 1$, respectively. Subjects who received an implanted device that provided PS rather than AS served as control for the AS group. Included subjects had experienced migraine for an average of 22.0 years prior to the study (range, 1-51 years). A responder was defined as a subject who achieved a $50 \%$ or greater reduction in the number of headache days per month or a three-point or greater reduction in average overall pain intensity compared with baseline. Three-month responder rates were 39\% for AS, 6\% for PS, and $0 \%$ for MM. However, lead migration occurred in 12 patients (24\%). In another randomised, controlled multicenter study, patients diagnosed with CM were implanted with an occipital nerve stimulator and randomised 2:1 to active $(n=105)$ or sham $(n=52)$ stimulation [166]. The study failed to meet its primary endpoint, a difference in the percentage of responders (defined as patients that achieved a $\geq 50 \%$ reduction in mean daily visual analogue scale (VAS) scores) in each group at 12 weeks but showed reductions in pain, headache days, and migraine-related disability. Although the authors also tried to investigate the safety of ONS in $\mathrm{CM}$, the 12-week follow-up is inadequate to answer this. Two other randomised controlled trials are available, one with a small number of patients [167] and the other only published in abstract form [168]. However, the results of all these trials have not been as significant as anticipated and more promising results have been obtained in chronic cluster headaches, although no RCTs have been conducted. For this reason, ONS for CM is only considered on an off-labelled basis. Long-term efficacy and safety of ONS still need to be addressed.

4.3.3. Supraorbital Nerve Stimulation. The first case of intractable cluster headache responding to percutaneous supraorbital nerve stimulation (SONS) was published in 2007 [169]. There are no studies investigating the use of SONS alone in patients with migraine. However, in combination with ONS, it has been used to treat CM $[170,171]$. Dual ONS and SONS for CM were studied in fourteen patients with follow-up ranging from 3 to 60 months [170]. Successful stimulation, defined as a $50 \%$ or greater reduction in pain severity, was seen in $71 \%$, with a mean reduction in headache-related VAS score of $3.92 \pm 2.4$. Half of the patients also had resolution of migraine-associated neurological symptoms and returned to normal functional capacity. A high rate of lead migration was observed $(42.8 \%)$, with other major adverse events being supraorbital lead allodynia (21.4\%) and infection (14.2\%). The reoperation rate was also high (35.7\%). Dual stimulation was superior to the positive response rates ( $\geq 50 \%$ pain reduction) in the published studies of ONS for CM. Reed et al. [171] described 7 patients with CM, 3 of which met Schulman's criteria for refractory migraines [172], in whom bilateral combined ON-SON stimulators were implanted [171]. All of the patients reported significant improvement in headache frequency and severity and return to a fully active lifestyle. However, larger randomised controlled trials with long-term follow-up are needed to confirm its efficacy and assess its safety.
More promising is the development of a new noninvasive supraorbital transcutaneous stimulator (STS) for migraines. The prevention of migraine using the Cefaly device (PREMICE Study) was a randomised, sham-controlled trial assessing the efficacy and safety of trigeminal neurostimulation with a STS [173]. Sixty-seven patients were randomised to either verum or sham stimulation with the stimulator applied for 20 minutes daily for 3 months. The primary outcome of $50 \%$ responder rate was significantly higher $(38.1 \%)$ in the verum group than in the sham group (12.1\%). The Cefaly device was found to be safe and well-tolerated in a patients' satisfaction survey involving 2313 participants, with $53.4 \%$ of patients willing to purchase the device [174]. The US Food and Drug Administration (FDA) granted approval for the marketing of the Cefaly device in March 2014. It is small and reasonably priced [175]. This is currently being appraised by NICE although funding through the NHS remains doubtful.

\section{Conclusion}

There is array of options for the acute and prophylactic management of migraine; some are more effective than others. The choice of a prophylactic agent should be tailored to the patient's needs and expectations, bearing in mind that their side effects can differ. We recommend the use of topiramate, amitriptyline, and propranolol as first-line prophylactics. However, in the future, it is likely that the noninvasive options such as TMS and Cefaly will become more widely accessible as prices are lowered. Invasive techniques such as percutaneous ONS or SONS should be reserved for those who have failed to respond to or did not tolerate all conventional treatments due to the risks associated with these interventions and the lack of long-term data on safety and efficacy.

\section{Conflict of Interests}

The authors declare that there is no conflict of interests regarding the publication of this paper.

\section{References}

[1] T. J. Steiner, A. I. Scher, W. F. Stewart, K. Kolodner, J. Liberman, and R. B. Lipton, "The prevalence and disability burden of adult migraine in England and their relationships to age, gender and ethnicity," Cephalalgia, vol. 23, no. 7, pp. 519-527, 2003.

[2] T. J. Steiner, L. J. Stovner, and G. L. Birbeck, "Migraine: the seventh disabler," The Journal of Headache and Pain, vol. 14, article 1, 2013.

[3] J. L. Natoli, A. Manack, B. Dean et al., "Global prevalence of chronic migraine: a systematic review," Cephalalgia, vol. 30, no. 5, pp. 599-609, 2010.

[4] M. E. Bigal, "The paradoxical effects of analgesics and the development of chronic migraine," Arquivos de Neuro-Psiquiatria, vol. 69, no. 3, pp. 544-551, 2011.

[5] IHS, "The international classification of headache disorders, 3rd edition (beta version)," Cephalalgia, vol. 33, no. 33, pp. 629-808, 2013. 
[6] C. E. Clarke, L. MacMillan, S. Sondhi, and N. E. J. Wells, "Economic and social impact of migraine," QJM-Monthly Journal of the Association of Physicians, vol. 89, no. 1, pp. 77-84, 1996.

[7] L. J. Stovner and C. Andrée, "Impact of headache in Europe: a review for the Eurolight project," Journal of Headache and Pain, vol. 9, no. 3, pp. 139-146, 2008.

[8] G. D. Solomon and K. L. Price, "Burden of migraine. A review of its socioeconomic impact," PharmacoEconomics, vol. 11, no. 1, pp. 1-10, 1997.

[9] F. M. Cutrer, "Pathophysiology of migraine," Seminars in Neurology, vol. 30, no. 2, pp. 120-130, 2010.

[10] J. Olesen, L. Friberg, T. S. Olsen et al., "Timing and topography of cerebral blood flow, aura, and headache during migraine attacks," Annals of Neurology, vol. 28, no. 6, pp. 791-798, 1990.

[11] M. Lauritzen, "Pathophysiology of the migraine aura. The spreading depression theory," Brain, vol. 117, no. 1, pp. 199-210, 1994.

[12] C. Ayata, "Cortical spreading depression triggers migraine attack: pro," Headache, vol. 50, no. 4, pp. 725-730, 2010.

[13] J. Olesen, R. Burstein, M. Ashina, and P. Tfelt-Hansen, "Origin of pain in migraine: evidence for peripheral sensitisation," The Lancet Neurology, vol. 8, no. 7, pp. 679-690, 2009.

[14] D. Levy, "Migraine pain and nociceptor activation-where do we stand?" Headache, vol. 50, no. 5, pp. 909-916, 2010.

[15] A. C. Charles and S. M. Baca, "Cortical spreading depression and migraine," Nature Reviews Neurology, vol. 9, no. 11, pp. 637644, 2013

[16] H. Bolay, U. Reuter, A. K. Dunn, Z. Huang, D. A. Boas, and M. A. Moskowitz, "Intrinsic brain activity triggers trigeminal meningeal afferents in a migraine model," Nature Medicine, vol. 8, no. 2, pp. 136-142, 2002.

[17] K. Messlinger, U. Hanesch, M. Baumgartel, B. Trost, and R. F. Schmidt, "Innervation of the dura mater encephali of cat and rat: ultrastructure and calcitonin gene-related peptide-like and substance P-like immunoreactivity," Anatomy and Embryology, vol. 188, no. 3, pp. 219-237, 1993.

[18] G. A. Lambert, L. Truong, and A. S. Zagami, "Effect of cortical spreading depression on basal and evoked traffic in the trigeminovascular sensory system," Cephalalgia, vol. 31, no. 14, pp. 1439-1451, 2011.

[19] P. J. Goadsby, A. R. Charbit, A. P. Andreou, S. Akerman, and P. R. Holland, "Neurobiology of migraine," Neuroscience, vol. 161, no. 2, pp. 327-341, 2009.

[20] R. Burstein, X. Zhang, D. Levy, K. R. Aoki, and M. F. Brin, "Selective inhibition of meningeal nociceptors by botulinum neurotoxin type A: therapeutic implications for migraine and other pains," Cephalalgia, vol. 34, no. 11, pp. 853-869, 2014.

[21] N. T. Mathew, "Pathophysiology of chronic migraine and mode of action of preventive medications," Headache, vol. 51, no. 2, pp. 84-92, 2011.

[22] N. T. Mathew, J. Kailasam, and T. Seifert, "Clinical recognition of allodynia in migraine," Neurology, vol. 63, no. 5, pp. 848-852, 2004.

[23] M. A. Louter, J. E. Bosker, W. P. J. van Oosterhout et al., "Cutaneous allodynia as a predictor of migraine chronification," Brain, vol. 136, no. 11, pp. 3489-3496, 2013.

[24] S. K. Aurora, A. Kulthia, and P. M. Barrodale, "Mechanism of chronic migraine," Current Pain and Headache Reports, vol. 15, no. 1, pp. 57-63, 2011.
[25] S. K. Aurora, "Is chronic migraine one end of a spectrum of migraine or a separate entity?” Cephalalgia, vol. 29, no. 6, pp. 597-605, 2009.

[26] S. K. Aurora, "Spectrum of illness: understanding biological patterns and relationships in chronic migraine," Neurology, vol. 72, supplement 5, pp. S8-S13, 2009.

[27] S. K. Aurora, P. M. Barrodale, R. L. Tipton, and A. Khodavirdi, "Brainstem dysfunction in chronic migraine as evidenced by neurophysiological and positron emission tomography studies," Headache, vol. 47, no. 7, pp. 996-1003, 2007.

[28] H.-C. Diener, G. Bussone, H. de Liano et al., "Placebocontrolled comparison of effervescent acetylsalicylic acid, sumatriptan and ibuprofen in the treatment of migraine attacks," Cephalalgia, vol. 24, no. 11, pp. 947-954, 2004.

[29] C. Lampl, M. Voelker, and H. C. Diener, "Efficacy and safety of 1,000 mg effervescent aspirin: individual patient data metaanalysis of three trials in migraine headache and migraine accompanying symptoms," Journal of Neurology, vol. 254, no. 6, pp. 705-712, 2007.

[30] R. B. Lipton, J. S. Baggish, W. F. Stewart, J. R. Codispoti, and $\mathrm{M}$. Fu, "Efficacy and safety of acetaminophen in the treatment of migraine: results of a randomized, double-blind, placebo-controlled, population-based study," Archives of Internal Medicine, vol. 160, no. 22, pp. 3486-3492, 2000.

[31] H. Havanka-Kanniainen, "Treatment of acute migraine attack: ibuprofen and placebo compared," Headache, vol. 29, no. 8, pp. 507-509, 1989.

[32] K. M. A. Welch, "Naproxen sodium in the treatment of migraine," Cephalalgia, vol. 6, supplement 4, pp. 85-92, 1986.

[33] The Diclofenac-K/Sumatriptan Migraine Study Group, "Acute treatment of migraine attacks: efficacy and safety of a nonsteroidal anti-inflammatory drug, diclofenac-potassium, in comparison to oral sumatriptan and placebo," Cephalalgia, vol. 19, no. 4, pp. 232-240, 1999.

[34] H. Göbel, A. Heinze, U. Niederberger, T. Witt, and V. Zumbroich, "Efficacy of phenazone in the treatment of acute migraine attacks: a double-blind, placebo-controlled, randomized study," Cephalalgia, vol. 24, no. 10, pp. 888-893, 2004.

[35] V. V. Myllylä, H. Havanka, L. Herrala et al., "Tolfenamic acid rapid release versus sumatriptan in the acute treatment of migraine: comparable effect in a double-blind, randomized, controlled, parallel-group study," Headache, vol. 38, no. 3, pp. 201-207, 1998.

[36] R. B. Lipton, W. F. Stewart, R. E. Ryan Jr., J. Saper, S. Silberstein, and F. Sheftell, "Efficacy and safety of acetaminophen, aspirin, and caffeine in alleviating migraine headache pain-three double-blind, randomized, placebo-controlled trials," Archives of Neurology, vol. 55, no. 2, pp. 210-217, 1998.

[37] H.-C. Diener, V. Pfaffenrath, L. Pageler, H. Peil, and B. Aicher, "The fixed combination of acetylsalicylic acid, paracetamol and caffeine is more effective than single substances and dual combination for the treatment of headache: a multicentre, randomized, double-blind, single-dose, placebo-controlled parallel group study," Cephalalgia, vol. 25, no. 10, pp. 776-787, 2005.

[38] J. Goldstein, S. D. Silberstein, J. R. Saper, R. E. Ryan Jr., and R. B. Lipton, "Acetaminophen, aspirin, and caffeine in combination versus ibuprofen for acute migraine: results from a multicenter, double-blind, randomized, parallel-group, singledose, placebo-controlled study," Headache, vol. 46, no. 3, pp. 444-453, 2006. 
[39] D. Kudrow, H. M. Thomas, G. Ruoff et al., "Valdecoxib for treatment of a single, acute, moderate to severe migraine headache," Headache, vol. 45, no. 9, pp. 1151-1162, 2005.

[40] S. Evers, J. Áfra, A. Frese et al., "EFNS guideline on the drug treatment of migraine-revised report of an EFNS task force," European Journal of Neurology, vol. 16, no. 9, pp. 968-981, 2009.

[41] L. M. Ross-Lee, M. J. Eadie, V. Heazlewood, F. Bochner, and J. H. Tyrer, "Aspirin pharmacokinetics in migraine. The effect of metoclopramide," European Journal of Clinical Pharmacology, vol. 24, no. 6, pp. 777-785, 1983.

[42] J. Waelkens, "Dopamine blockade with domperidone: bridge between prophylactic and abortive treatment of migraine? A dose-finding study," Cephalalgia, vol. 4, no. 2, pp. 85-90, 1984.

[43] E. A. Schulman and K. F. Dermott, "Sumatriptan plus metoclopramide in triptan-nonresponsive migraineurs," Headache, vol. 43, no. 7, pp. 729-733, 2003.

[44] P. P. A. Humphrey, W. Feniuk, M. J. Perren, I. J. M. Beresford, M. Skingle, and E. T. Whalley, "Serotonin and migraine," Annals of the New York Academy of Sciences, vol. 600, pp. 587-598, 1990.

[45] M. A. Moskowitz and F. M. Cutrer, "Sumatriptan: a receptortargeted treatment for migraine," Annual Review of Medicine, vol. 44, pp. 145-154, 1993.

[46] P. J. Goadsby, “The pharmacology of headache," Progress in Neurobiology, vol. 62, no. 5, pp. 509-525, 2000.

[47] M. D. Ferrari, K. I. Roon, R. B. Lipton, and P. J. Goadsby, "Oral triptans (serotonin 5- $\mathrm{HT}_{1 \mathrm{~B} / \mathrm{ID}}$ agonists) in acute migraine treatment: a meta-analysis of 53 trials," The Lancet, vol. 358, no. 9294, pp. 1668-1675, 2001.

[48] C. G. H. Dahlöf, D. Dodick, A. J. Dowson, and J. Pascual, "How does almotriptan compare with other triptans? A review of data from placebo-controlled clinical trials," Headache, vol. 42, no. 2, pp. 99-113, 2002.

[49] M. D. Ferrari, P. J. Goadsby, K. I. Roon, and R. B. Lipton, "Triptans (serotonin, 5-HT1B/1D agonists) in migraine: detailed results and methods of a meta-analysis of 53 trials," Cephalalgia, vol. 22, no. 8, pp. 633-658, 2002.

[50] The Subcutaneous Sumatriptan International Study Group, "Treatment of migraine attacks with sumatriptan," The New England Journal of Medicine, vol. 325, no. 5, pp. 316-321, 1991.

[51] R. W. Evans and C. G. H. Dahlöf, "Determining triptan preference for the individual patient," Headache, vol. 44, no. 7, pp. 723-725, 2004.

[52] Z. Katsarava, G. Fritsche, M. Muessig, H. C. Diener, and V. Limmroth, "Clinical features of withdrawal headache following overuse of triptans and other headache drugs," Neurology, vol. 57, no. 9, pp. 1694-1698, 2001.

[53] The Multinational Oral Sumatriptan Cafergot Comparative Study Group, "A randomized, double-blind comparison of sumatriptan and cafergot in the acute treatment of migraine," European Neurology, vol. 31, no. 5, pp. 314-322, 1991.

[54] H.-C. Diener, J.-P. Jansen, A. Reches, J. Pascual, D. Pitei, and T. J. Steiner, "Efficacy, tolerability and safety of oral eletriptan and ergotamine plus caffeine (Cafergot) in the acute treatment of migraine: a multicentre, randomised, double-blind, placebocontrolled comparison," European Neurology, vol. 47, no. 2, pp. 99-107, 2002.

[55] R. P. Shank, J. F. Gardocki, A. J. Streeter, and B. E. Maryanoff, "An overview of the preclinical aspects of topiramate: pharmacology, pharmacokinetics, and mechanism of action," Epilepsia, vol. 41, no. 1, pp. S3-S9, 2000.
[56] S. Akerman and P. J. Goadsby, "Topiramate inhibits cortical spreading depression in rat and cat: impact in migraine aura," NeuroReport, vol. 16, no. 12, pp. 1383-1387, 2005.

[57] K. R. Edwards, M. J. Glantz, J. A. Norton, and N. Cross, "Prophylactic treatment of episodic migraine with topiramate: a doubleblind, placebo-controlled trial in 30 patients," Cephalalgia, vol. 20, p. 316, 2000.

[58] J. R. Storey, C. S. Calder, D. E. Hart, and D. L. Potter, "Topiramate in migraine prevention: a double-blind, placebocontrolled study," Headache, vol. 41, no. 10, pp. 968-975, 2001.

[59] J. L. Brandes, J. R. Saper, M. Diamond et al., "Topiramate for migraine prevention: a randomized controlled trial," The Journal of the American Medical Association, vol. 291, no. 8, pp. 965-973, 2004.

[60] S. D. Silberstein, W. Neto, J. Schmitt, and D. Jacobs, "Topiramate in migraine prevention: results of a large controlled trial," Archives of Neurology, vol. 61, no. 4, pp. 490-495, 2004.

[61] National Clinical Guideline Centre, Headaches. Diagnosis and Management of Headaches in Young People and Adults (Full NICE Guideline), Clinical Guideline 150, National Institute for Health and Care Excellence, 2012, http://www.nice.org.uk/.

[62] M. Silvestrini, M. Bartolini, M. Coccia, R. Baruffaldi, R. Taffi, and L. Provinciali, "Topiramate in the treatment of chronic migraine," Cephalalgia, vol. 23, no. 8, pp. 820-824, 2003.

[63] H.-C. Diener, G. Bussone, J. C. Van Oene, M. Lahaye, S. Schwalen, and P. J. Goadsby, "Topiramate reduces headache days in chronic migraine: a randomized, double-blind, placebocontrolled study," Cephalalgia, vol. 27, no. 7, pp. 814-823, 2007.

[64] J. Olesen, "The international classification of headache disorders, 2nd edition (ICHD-II)," Revue Neurologique, vol. 15, no. 6-7, pp. 689-691, 2005.

[65] S. D. Silberstein, R. B. Lipton, D. W. Dodick et al., "Efficacy and safety of topiramate for the treatment of chronic migraine: a randomized, double-blind, placebo-controlled trial," Headache, vol. 47, no. 2, pp. 170-180, 2007.

[66] J. D. Gomersall and A. Stuart, "Amitriptyline in migraine prophylaxis: changes in pattern of attacks during a controlled clinical trial," Journal of Neurology, Neurosurgery \& Psychiatry, vol. 36, no. 4, pp. 684-690, 1973.

[67] J. R. Couch and R. S. Hassanein, "Amitriptyline in migraine prophylaxis," Archives of Neurology, vol. 36, no. 11, pp. 695-699, 1979.

[68] D. W. Dodick, F. Freitag, J. Banks et al., “Topiramate versus amitriptyline in migraine prevention: a 26-week, multicenter, randomized, double-blind, double-dummy, parallel-group noninferiority trial in adult migraineurs," Clinical Therapeutics, vol. 31, no. 3, pp. 542-559, 2009.

[69] K. Linde and K. Rossnagel, "Propranolol for migraine prophylaxis," Cochrane Database of Systematic Reviews, vol. 2, Article ID CD003225, 2004.

[70] D. K. Ziegler, A. Hurwitz, R. S. Hassanein, H. A. Kodanaz, S. H. Preskorn, and J. Mason, "Migraine prophylaxis. A comparison of propranolol and amitriptyline," Archives of Neurology, vol. 44, no. 5, pp. 486-489, 1987.

[71] A. Pradalier, G. Serratrice, M. Collard et al., "Long-acting propranolol in migraine prophylaxis: results of a double-blind, placebo-controlled study," Cephalalgia, vol. 9, no. 4, pp. 247-253, 1989.

[72] P. Kangasniemi and C. Hedman, "Metoprolol and propranolol in the prophylactic treatment of classical and common migraine. A double-blind study," Cephalalgia, vol. 4, no. 2, pp. 91-98, 1984. 
[73] J. E. Olsson, H. C. Behring, B. Forssman et al., "Metoprolol and propranolol in migraine prophylaxis: a double-blind multicentre study," Acta Neurologica Scandinavica, vol. 70, no. 3, pp. 160 $168,1984$.

[74] T. J. Steiner, R. Joseph, C. Hedman, and F. C. Rose, "Metoprolol in the prophylaxis of migraine: parallel-groups comparison with placebo and dose-ranging follow-up," Headache, vol. 28, no. 1, pp. 15-23, 1988.

[75] P. Tfelt-Hansen, B. Standnes, P. Kangasneimi, H. Hakkarainen, and J. Olesen, "Timolol vs propranolol vs placebo in common migraine prophylaxis: a double-blind multicenter trial," Acta Neurologica Scandinavica, vol. 69, no. 1, pp. 1-8, 1984.

[76] B. Olerud, C. L. Gustavsson, and B. Furberg, "Nadolol and propranolol in migraine management," Headache, vol. 26, no. 10, pp. 490-493, 1986.

[77] R. Worz, B. Reinhardt-Benmalek, K.-H. Grotemeyer, and M. Foh, "Bisoprolol and metoprolol in the prophylactic treatment of migraine with and without aura-a randomized double-blind cross-over multicenter study," Cephalalgia, vol. 11, no. 11, pp. 152-153, 1991.

[78] V. Johannsson, L. R. Nilsson, T. Widelius et al., "Atenolol in migraine prophylaxis a double-blind cross-over multicentre study," Headache, vol. 27, no. 7, pp. 372-374, 1987.

[79] F. M. Cutrer and M. A. Moskowitz, "The actions of valproate and neurosteroids in a model of trigeminal pain," Headache, vol. 36, no. 10, pp. 579-585, 1996.

[80] R. Hering and A. Kuritzky, "Sodium valproate in the prophylactic treatment of migraine: a double-blind study versus placebo," Cephalalgia, vol. 12, no. 2, pp. 81-84, 1992.

[81] J. Klapper, "Divalproex sodium in migraine prophylaxis: a dosecontrolled study," Cephalalgia, vol. 17, no. 2, pp. 103-108, 1997.

[82] S. D. Silberstein, S. D. Collins, and H. Carlson, "Safety and efficacy of once-daily, extended-release divalproex sodium monotherapy for the prophylaxis of migraine headaches," Cephalalgia, vol. 20, p. 269, 2000.

[83] F. G. Freitag, S. D. Collins, H. A. Carlson et al., "A randomized trial of divalproex sodium extended-release tablets in migraine prophylaxis," Neurology, vol. 58, no. 11, pp. 1652-1659, 2002.

[84] R. G. Kaniecki, "A comparison of divalproex with propranolol and placebo for the prophylaxis of migraine without aura," Archives of Neurology, vol. 54, no. 9, pp. 1141-1145, 1997.

[85] D. D. Mitsikostas and I. Polychronidis, "Valproate versus flunarizine in migraine prophylaxis: a randomized, double-open, clinical trial," Functional Neurology, vol. 12, no. 5, pp. 267-276, 1997.

[86] M. Linde, W. M. Mulleners, E. P. Chronicle, and D. C. McCrory, "Valproate (valproic acid or sodium valproate or a combination of the two) for the prophylaxis of episodic migraine in adults," Cochrane Database of Systematic Reviews, vol. 6, Article ID CD010611, 2013.

[87] P. Louis, "A double-blind placebo-controlled prophylactic study of flunarizine (Sibelium) in migraine," Headache, vol. 21, no. 6, pp. 235-239, 1981.

[88] F. G. Freitag, S. Diamond, and M. Diamond, "A placebo controlled trial of flunarizine in migraine prophylaxis," Cephalalgia, vol. 11, supplement 11, pp. 157-158, 1991.

[89] S. Diamond and F. G. Freitag, "A double blind trial of flunarizine in migraine prophylaxis," Headache Quarterly, vol. 4, no. 2, pp. 169-172, 1993.

[90] H. C. Diener, J. Matias-Guiu, E. Hartung et al., "Efficacy and tolerability in migraine prophylaxis of flunarizine in reduced doses: a comparison with propranolol $160 \mathrm{mg}$ daily," Cephalalgia, vol. 22, no. 3, pp. 209-221, 2002.

[91] C. H. Lucking, W. Oestreich, R. Schmidt, and D. Soyka, "Flunarizine vs propranolol in the prophylaxis of migraine: two double-blind comparative studies in more than 400 patients," Cephalalgia, vol. 8, supplement 8, pp. 21-26, 1988.

[92] N. Luo, W. Di, A. Zhang et al., "A randomized, one-year clinical trial comparing the efficacy of topiramate, flunarizine, and a combination of flunarizine and topiramate in migraine prophylaxis," Pain Medicine, vol. 13, no. 1, pp. 80-86, 2012.

[93] G. Nappi, G. Sandrini, G. Savoini, A. Cavallini, C. de Rysky, and G. Micieli, "Comparative efficacy of cyclandelate versus flunarizine in the prophylactic treatment of migraine," Drugs, vol. 33, supplement 2, pp. 103-109, 1987.

[94] W.-D. Gerber, R. Schellenberg, M. Thom et al., "Cyclandelate versus propranolol in the prophylaxis of migraine-a doubleblind placebo-controlled study," Functional Neurology, vol. 10, no. 1, pp. 27-35, 1995.

[95] H. C. Diener, M. Föh, C. Iaccarino et al., "Cyclandelate in the prophylaxis of migraine: a randomized, parallel, double-blind study in comparison with placebo and propranolol," Cephalalgia, vol. 16, no. 6, pp. 441-447, 1996.

[96] M. Siniatchkin, W.-D. Gerber, and A. Vein, "Clinical efficacy and central mechanisms of cyclandelate in migraine: a doubleblind placebo-controlled study," Functional Neurology, vol. 13, no. 1, pp. 47-56, 1998.

[97] H.-C. Diener, P. Krupp, T. Schmitt et al., "Cyclandelate in the prophylaxis of migraine: a placebo-controlled study," Cephalalgia, vol. 21, no. 1, pp. 66-70, 2001.

[98] A. Bostani, A. Rajabi, N. Moradian, N. Razazian, and M. Rezaei, "The effects of cinnarizine versus sodium valproate in migraine prophylaxis," International Journal of Neuroscience, vol. 123, no. 7, pp. 487-493, 2013.

[99] P. Rossi, G. Fiermonte, and F. Pierelli, "Cinnarizine in migraine prophylaxis: efficacy, tolerability and predictive factors for therapeutic responsiveness: an open-label pilot trial," Functional Neurology, vol. 18, no. 3, pp. 155-159, 2003.

[100] M. Togha, H. Ashrafian, and P. Tajik, "Open-label trial of cinnarizine in migraine prophylaxis," Headache, vol. 46, no. 3 , pp. 498-502, 2006.

[101] H. J. Gelmers, "Nimodipine, a new calcium antagonist, in the prophylactic treatment of migraine," Headache, vol. 23, no. 3, pp. 106-109, 1983.

[102] G. Bussone, S. Baldini, G. D’Andrea et al., "Nimodipine versus flunarizine in common migraine: a controlled pilot trial," Headache, vol. 27, no. 2, pp. 76-79, 1987.

[103] H. Havanka-Kanniainen, E. Hokkanen, and V. V. Myllylä, "Efficacy of nimodipine in the prophylaxis of migraine," Cephalalgia, vol. 5, no. 1, pp. 39-43, 1985.

[104] S. Silberstein, S. Goode-Sellers, C. Twomey, J. Saiers, and J. Ascher, "Randomized, double-blind, placebo-controlled, phase II trial of gabapentin enacarbil for migraine prophylaxis," Cephalalgia, vol. 33, no. 2, pp. 101-111, 2013.

[105] T. J. Steiner, L. J. Findley, and A. W. C. Yuen, "Lamotrigine versus placebo in the prophylaxis of migraine with and without aura," Cephalalgia, vol. 17, no. 2, pp. 109-112, 1997.

[106] S. Silberstein, J. Saper, F. Berenson, M. Somogyi, K. McCague, and J. D'Souza, "Oxcarbazepine in migraine headache: a doubleblind, randomized, placebo-controlled study," Neurology, vol. 70, no. 7, pp. 548-555, 2008. 
[107] E. Tronvik, L. J. Stovner, G. Helde, T. Sand, and G. Bovim, "Prophylactic treatment of migraine with an angiotensin II receptor blocker: a randomized controlled trial," The Journal of the American Medical Association, vol. 289, no. 1, pp. 65-69, 2003.

[108] L. J. Stovner, M. Linde, G. B. Gravdahl et al., "A comparative study of candesartan versus propranolol for migraine prophylaxis: a randomised, triple-blind, placebo-controlled, double cross-over study," Cephalalgia, vol. 34, no. 7, pp. 523-532, 2013.

[109] H. Schrader, L. J. Stovner, G. Helde, T. Sand, and G. Bovim, "Prophylactic treatment of migraine with angiotensin converting enzyme inhibitor (lisinopril): randomised, placebo controlled, crossover study," British Medical Journal, vol. 322, no. 7277, pp. 19-22, 2001.

[110] C. Adly, J. Straumanis, and A. Chesson, "Fluoxetine prophylaxis of migraine," Headache, vol. 32, no. 2, pp. 101-104, 1992.

[111] J. R. Saper, S. D. Silberstein, A. E. Lake III, and M. E. Winters, "Double-blind trial of fluoxetine: chronic daily headache and migraine," Headache, vol. 34, no. 9, pp. 497-502, 1994.

[112] S. N. Ozyalcin, G. K. Talu, E. Kiziltan, B. Yucel, M. Ertas, and R. Disci, "The efficacy and safety of venlafaxine in the prophylaxis of migraine," Headache, vol. 45, no. 2, pp. 144-152, 2005.

[113] S. Bulut, M. S. Berilgen, A. Baran, A. Tekatas, M. Atmaca, and B. Mungen, "Venlafaxine versus amitriptyline in the prophylactic treatment of migraine: randomized, double-blind, crossover study," Clinical Neurology and Neurosurgery, vol. 107, no. 1, pp. 44-48, 2004.

[114] J. D. Carroll and W. P. Maclay, "Pizotifen (BC 105) in migraine prophylaxis," Current Medical Research and Opinion, vol. 3, no. 2, pp. 68-71, 1975.

[115] P. Kangasniemi, "Placebo, 1-isopropylnoradrenochrome 5 monosemicarbazone and pizotifen in migraine prophylaxis," Headache, vol. 19, no. 4, pp. 219-222, 1979.

[116] P. Hübbe, "The prophylactic treatment of migraine with an antiserotonin pizotifen," Acta Neurologica Scandinavica, vol. 49, no. 1, pp. 108-114, 1973.

[117] M. Gawel, "A double-blind, cross-over study of nimodipine versus pizotyline in common and classical migraine," Cephalalgia, vol. 7, supplement 6, pp. 453-454, 1987.

[118] P. O. Osterman, "A comparison between placebo, pizotifen and 1 isopropyl 3 hydroxy 5 semicarbazono 6 oxo 2.3.5.6 tetrahydroindol (Divascan) in migraine prophylaxis," Acta Neurologica Scandinavica, vol. 56, no. 1, pp. 17-28, 1977.

[119] R. N. Gray, R. E. Goslin, D. C. McCrory, K. Eberlein, J. Tulsky, and V. Hasselblad, "Drug treatments for the prevention of migraine headache," Technical Review 2.3, 1999, (Prepared for the Agency for Health Care Policy and Research under Contract No. 290-94-2025. Available from the National Technical Information Service; NTIS Accession No. 127953.).

[120] B. Kåss and K. Nestvold, "Propranolol (Inderal) and clonidine (Catapressan) in the prophylactic treatment of migraine: a comparative trial," Acta Neurologica Scandinavica, vol. 61, no. 6, pp. 351-356, 1980.

[121] P. Louis, J. Schoenen, and C. Hedman, "Metoprolol v. clonidine in the prophylactic treatment of migraine," Cephalalgia, vol. 5, no. 3, pp. 159-165, 1985.

[122] U. Danesch and R. Rittinghausen, "Safety of a patented special butterbur root extract for migraine prevention," Headache, vol. 43, no. 1, pp. 76-78, 2003.

[123] R. B. Lipton, H. Göbel, K. M. Einhäupl, K. Wilks, and A. Mauskop, "Petasites hybridus root (butterbur) is an effective preventive treatment for migraine," Neurology, vol. 63, no. 12, pp. 2240-2244, 2004.

[124] H. C. Diener, V. W. Rahlfs, and U. Danesch, “The first placebocontrolled trial of a special butterbur root extract for the prevention of migraine: reanalysis of efficacy riteria," European Neurology, vol. 51, no. 2, pp. 89-97, 2004.

[125] M. H. Pittler and E. Ernst, "Feverfew for preventing migraine," Cochrane Database of Systematic Reviews, vol. 1, Article ID CD002286, 2004.

[126] J. Schoenen, J. Jacquy, and M. Lenaerts, "Effectiveness of highdose riboflavin in migraine prophylaxis. a randomized controlled trial," Neurology, vol. 50, no. 2, pp. 466-470, 1998.

[127] A. Peikert, C. Wilimzig, and R. Köhne-Volland, "Prophylaxis of migraine with oral magnesium: results from a prospective, multi-center, placebo-controlled and double-blind randomized study," Cephalalgia, vol. 16, no. 4, pp. 257-263, 1996.

[128] V. Pfaffenrath, P. Wessely, C. Meyer et al., "Magnesium in the prophylaxis of migraine-a double-blind, placebo-controlled study," Cephalalgia, vol. 16, no. 6, pp. 436-440, 1996.

[129] F. Facchinetti, G. Sances, P. Borella, A. R. Genazzani, and G. Nappi, "Magnesium prophylaxis of menstrual migraine: effects of intracellular magnesium," Headache, vol. 31, no. 5, pp. 298301, 1991.

[130] R. Gooriah and F. Ahmed, "Therapeutic uses of botulinum toxin," Journal of Clinical Toxicology, vol. 5, article 225, 2015.

[131] W. J. Binder, M. F. Brin, A. Blitzer, L. D. Schoenrock, and J. M. Pogoda, "Botulinum toxin type a (BOTOX) for treatment of migraine headaches: an open-label study," OtolaryngologyHead and Neck Surgery, vol. 123, no. 6, pp. 669-676, 2000.

[132] F. G. Freitag, S. Diamond, M. Diamond, and G. Urban, "Botulinum toxin type $\mathrm{A}$ in the treatment of chronic migraine without medication overuse," Headache, vol. 48, no. 2, pp. 201-209, 2008.

[133] S. K. Aurora, D. W. Dodick, C. C. Turkel et al., "OnabotulinumtoxinA for treatment of chronic migraine: results from the double-blind, randomized, placebo-controlled phase of the PREEMPT 1 trial," Cephalalgia, vol. 30, no. 7, pp. 793-803, 2010.

[134] H. C. Diener, D. W. Dodick, S. K. Aurora et al., "OnabotulinumtoxinA for treatment of chronic migraine: results from the double-blind, randomized, placebo-controlled phase of the PREEMPT 2 trial," Cephalalgia, vol. 30, no. 7, pp. 804-814, 2010.

[135] D. W. Dodick, C. C. Turkel, R. E. DeGryse et al., "OnabotulinumtoxinA for treatment of chronic migraine: pooled results from the double-blind, randomized, placebo-controlled phases of the PREEMPT clinical program," Headache, vol. 50, no. 6, pp. 921-936, 2010.

[136] F. Ahmed and R. Gooriah, "OnabotulinumtoxinA for chronic migraine: a critical appraisal," Therapeutics and Clinical Risk Management, vol. 11, pp. 1003-1013, 2015.

[137] A. Ashkenazi and M. Levin, "Greater occipital nerve block for migraine and other headaches: is it useful?" Current Pain and Headache Reports, vol. 11, no. 3, pp. 231-235, 2007.

[138] W. B. Young, "Blocking the greater occipital nerve: utility in headache management," Current Pain and Headache Reports, vol. 14, no. 5, pp. 404-408, 2010.

[139] S. K. Afridi, K. G. Shields, R. Bhola, and P. J. Goadsby, "Greater occipital nerve injection in primary headache syndromes: prolonged effects from a single injection," Pain, vol. 122, no. 1-2, pp. 126-129, 2006.

[140] M. J. Gawel and P. J. Rothbart, "Occipital nerve block in the management of headache and cervical pain," Cephalalgia, vol. 12, no. 1, pp. 9-13, 1992. 
[141] F. Ceccherelli, F. Ambrosio, M. Avila, G. Duse, A. Munari, and G. P. Giron, "Acupuncture vs. placebo in the common migraine: a double-blind study," Cephalalgia, vol. 7, supplement 6, pp. 499-500, 1987.

[142] G. Allais, C. De Lorenzo, P. E. Quirico et al., "Acupuncture in the prophylactic treatment of migraine without aura: a comparison with flunarizine," Headache, vol. 42, no. 9, pp. 855-861, 2002.

[143] M. A. Linde, J. Y. Carlsson, and C. G. H. Dahlöf, "Impact of acupuncture as add-on therapy to pharmacological treatment of migraine: a pilot study," Pain Clinic, vol. 12, no. 3, pp. 247$252,2000$.

[144] J. Alecrim-Andrade, J. A. Maciel-Júnior, X. Carne i Cladellas, H. R. Correa-Filho, H. C. Machado, and G. M. S. Vasconcelos, "Efficacy of acupuncture in migraine attack prophylaxis: a randomized sham-controlled trial," Cephalalgia, vol. 25, no. 10, article 942, 2005.

[145] K. Linde, A. Streng, S. Jürgens et al., "Acupuncture for patients with migraine: a randomized controlled trial," The Journal of the American Medical Association, vol. 293, no. 17, pp. 2118-2125, 2005.

[146] H.-C. Diener, K. Kronfeld, G. Boewing et al., "Efficacy of acupuncture for the prophylaxis of migraine: a multicentre randomised controlled clinical trial," The Lancet Neurology, vol. 5, no. 4, pp. 310-316, 2006.

[147] E. Facco, A. Liguori, F. Petti et al., "Traditional acupuncture in migraine: a controlled, randomized study," Headache, vol. 48, no. 3, pp. 398-407, 2008.

[148] A. Streng, K. Linde, A. Hoppe et al., "Effectiveness and tolerability of acupuncture compared with metoprolol in migraine prophylaxis," Headache, vol. 46, no. 10, pp. 1492-1502, 2006.

[149] A. Hróbjartsson and P. C. Gøtzsche, "Placebo interventions for all clinical conditions," Cochrane Database of Systematic Reviews, no. 1, Article ID CD003974, 2010.

[150] K. Linde, K. Niemann, and K. Meissner, "Are sham acupuncture interventions more effective than (other) placebos? A reanalysis of data from the cochrane review on placebo effects," Forschende Komplementarmedizin, vol. 17, no. 5, pp. 259-264, 2010.

[151] H. H. Moffet, "Sham acupuncture may be as efficacious as true acupuncture: a systematic review of clinical trials," Journal of Alternative and Complementary Medicine, vol. 15, no. 3, pp. 213216, 2009.

[152] K. Linde, G. Allais, B. Brinkhaus, E. Manheimer, A. Vickers, and A. R. White, "Acupuncture for migraine prophylaxis," Cochrane Database of Systematic Reviews, no. 1, Article ID CD001218, 2009.

[153] R. Hassanzadeh, J. C. Jones, and E. L. Ross, "Neuromodulation for intractable headaches," Current Pain and Headache Reports, vol. 18, article 392, 2014.

[154] B. M. Clarke, A. R. M. Upton, M. V. Kamath, T. Al-Harbi, and C. M. Castellanos, "Transcranial magnetic stimulation for migraine: clinical effects," Journal of Headache and Pain, vol. 7, no. 5, pp. 341-346, 2006.

[155] T. M. Mohammad, G. Hughes, and M. Nkrumah, "Selfadministered transcranial magnetic stimulation (TMS) during the aura phase improved and aborts headache," Headache, vol. 46, p. 857, 2006.

[156] R. B. Lipton, D. W. Dodick, S. D. Silberstein et al., "Singlepulse transcranial magnetic stimulation for acute treatment of migraine with aura: a randomised, double-blind, parallelgroup, sham-controlled trial," The Lancet Neurology, vol. 9, no. 4, pp. 373-380, 2010.
[157] F. Brighina, A. Piazza, G. Vitello et al., "rTMS of the prefrontal cortex in the treatment of chronic migraine: a pilot study," Journal of the Neurological Sciences, vol. 227, no. 1, pp. 67-71, 2004.

[158] M. Teepker, J. Hötzel, N. Timmesfeld et al., "Low-frequency rTMS of the vertex in the prophylactic treatment of migraine," Cephalalgia, vol. 30, no. 2, pp. 137-144, 2010.

[159] U. K. Misra, J. Kalita, and S. K. Bhoi, "High-rate repetitive transcranial magnetic stimulation in migraine prophylaxis: a randomized, placebo-controlled study," Journal of Neurology, vol. 260, no. 11, pp. 2793-2801, 2013.

[160] R. B. Lipton and S. H. Pearlman, "Transcranial magnetic simulation in the treatment of migraine," Neurotherapeutics, vol. 7, no. 2, pp. 204-212, 2010.

[161] http://www.eneura.com/.

[162] D. W. Dodick, "Occipital nerve stimulation for chronic cluster headache," Advanced Studies in Medicine, vol. 3, no. 6, pp. S569S571, 2003.

[163] C. A. Popeney and K. M. Aló, "Peripheral neurostimulation for the treatment of chronic, disabling transformed migraine," Headache, vol. 43, no. 4, pp. 369-375, 2003.

[164] M. S. Matharu, T. Bartsch, N. Ward, R. S. J. Frackowiak, R. Weiner, and P. J. Goadsby, "Central neuromodulation in chronic migraine patients with suboccipital stimulators: a PET study," Brain, vol. 127, no. 1, pp. 220-230, 2004.

[165] J. R. Saper, D. W. Dodick, S. D. Silberstein, S. McCarville, M. Sun, and P. J. Goadsby, "Occipital nerve stimulation for the treatment of intractable chronic migraine headache: ONSTIM feasibility study," Cephalalgia, vol. 31, no. 3, pp. 271-285, 2011.

[166] S. D. Silberstein, D. W. Dodick, J. Saper et al., "Safety and efficacy of peripheral nerve stimulation of the occipital nerves for the management of chronic migraine: results from a randomized, multicenter, double-blinded, controlled study," Cephalalgia, vol. 32, no. 16, pp. 1165-1179, 2012.

[167] G. Serra and F. Marchioretto, "Occipital nerve stimulation for chronic migraine: a randomized trial," Pain Physician, vol. 15, no. 3, pp. 245-253, 2012.

[168] R. Lipton, P. Goadsby, R. Cady et al., "PRISM study: occipital nerve stimulation for treatment-refractory migraine," Cephalalgia, vol. 29, pp. 1-166, 2009, abstract P047.

[169] S. N. Narouze and L. Kapural, "Supraorbital nerve electric stimulation for the treatment of intractable chronic cluster headache: a case report," Headache, vol. 47, no. 7, pp. 1100-1102, 2007.

[170] S. Hann and A. Sharan, "Dual occipital and supraorbital nerve stimulation for chronic migraine: a single-center experience, review of literature, and surgical considerations," Neurosurgical Focus, vol. 35, no. 3, article E9, 2013.

[171] K. L. Reed, S. B. Black, C. J. Banta II, and K. R. Will, “Combined occipital and supraorbital neurostimulation for the treatment of chronic migraine headaches: initial experience," Cephalalgia, vol. 30, no. 3, pp. 260-271, 2010.

[172] E. A. Schulman, A. E. Lake III, P. J. Goadsby et al., "Defining refractory migraine and refractory chronic migraine: proposed criteria from the refractory headache special interest section of the American Headache Society," Headache, vol. 48, no. 6, pp. 778-782, 2008.

[173] J. Schoenen, B. Vandersmissen, S. Jeangette et al., "Migraine prevention with a supraorbital transcutaneous stimulator: a randomized controlled trial," Neurology, vol. 80, no. 8, pp. 697704, 2013. 
[174] D. Magis, S. Sava, T. S. d'Elia, R. Baschi, and J. Schoenen, "Safety and patients' satisfaction of transcutaneous supraorbital neurostimulation (tSNS) with the Cefaly device in headache treatment: a survey of 2,313 headache sufferers in the general population," The Journal of Headache and Pain, vol. 14, article 95, 2013.

[175] Cefaly, http://www.cefaly.co.uk. 


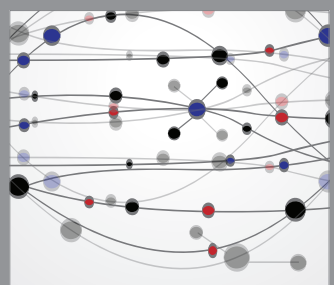

The Scientific World Journal
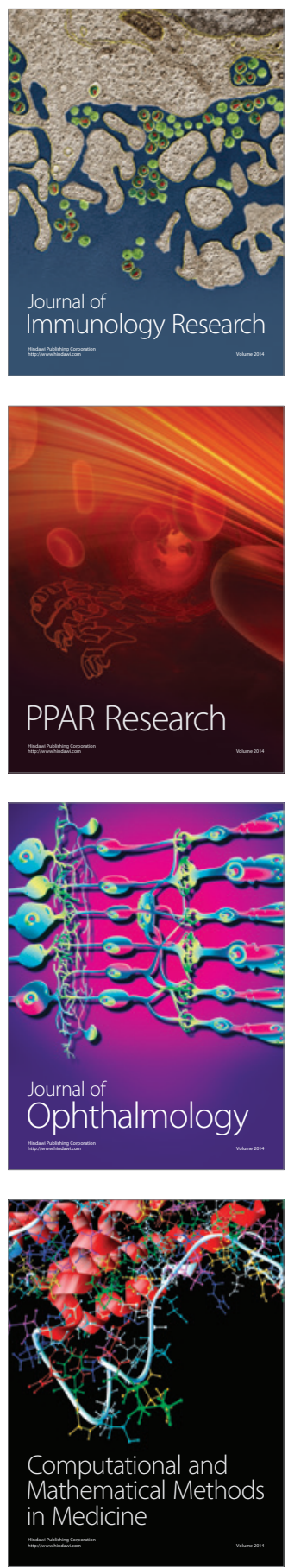

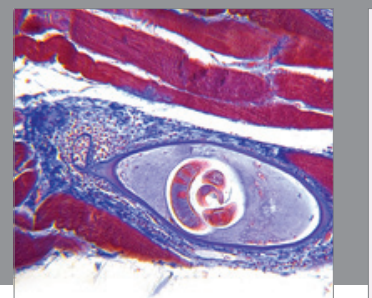

Gastroenterology

Research and Practice
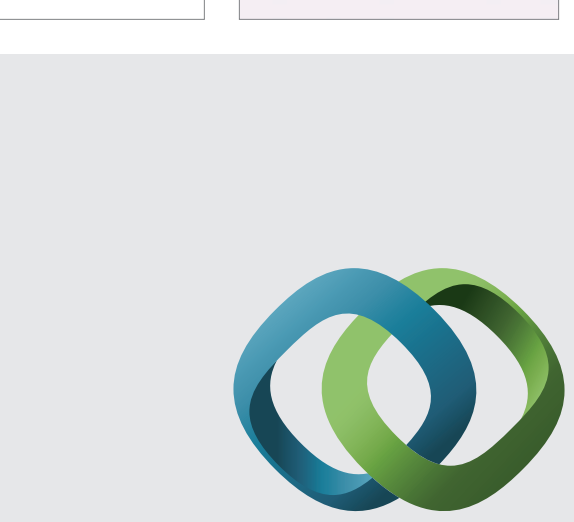

\section{Hindawi}

Submit your manuscripts at

http://www.hindawi.com
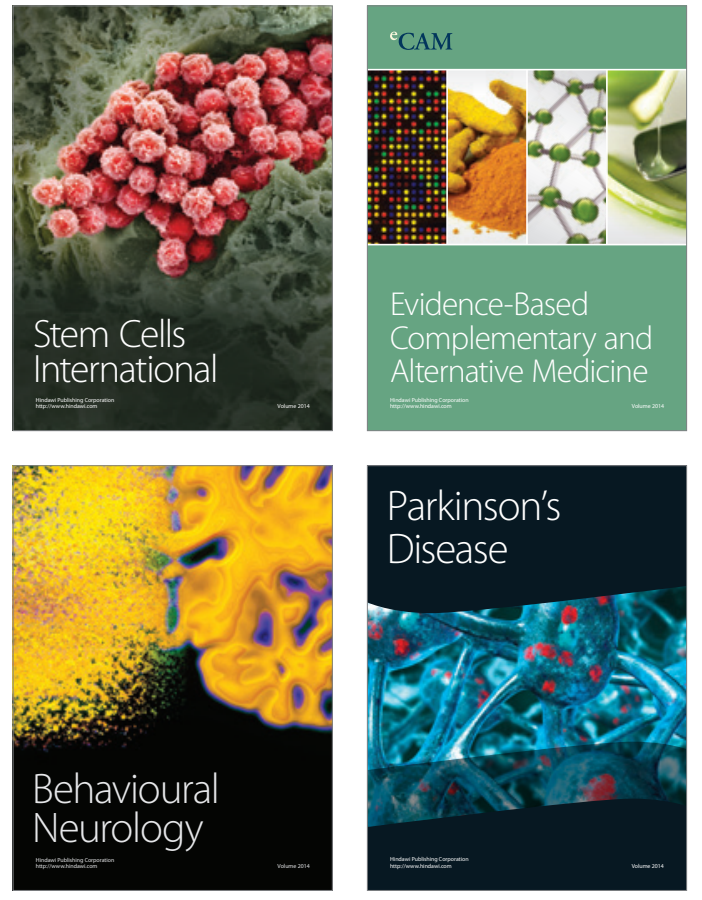
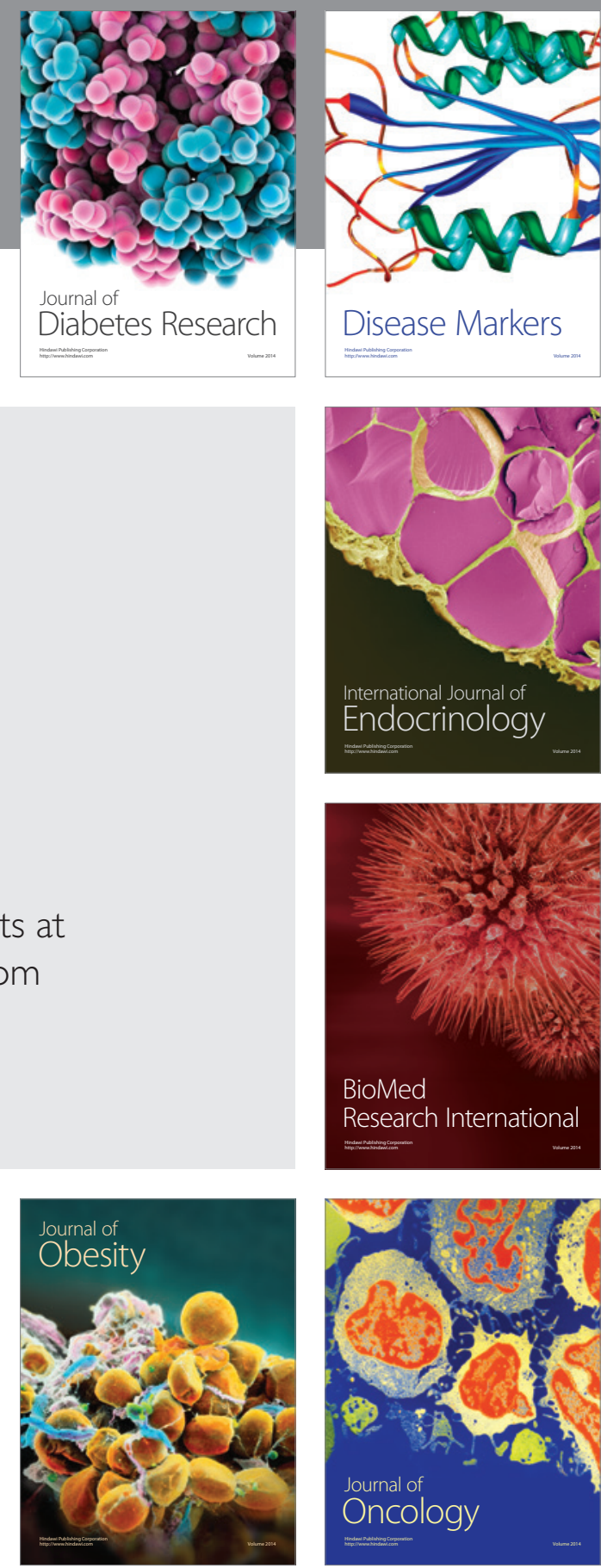

Disease Markers
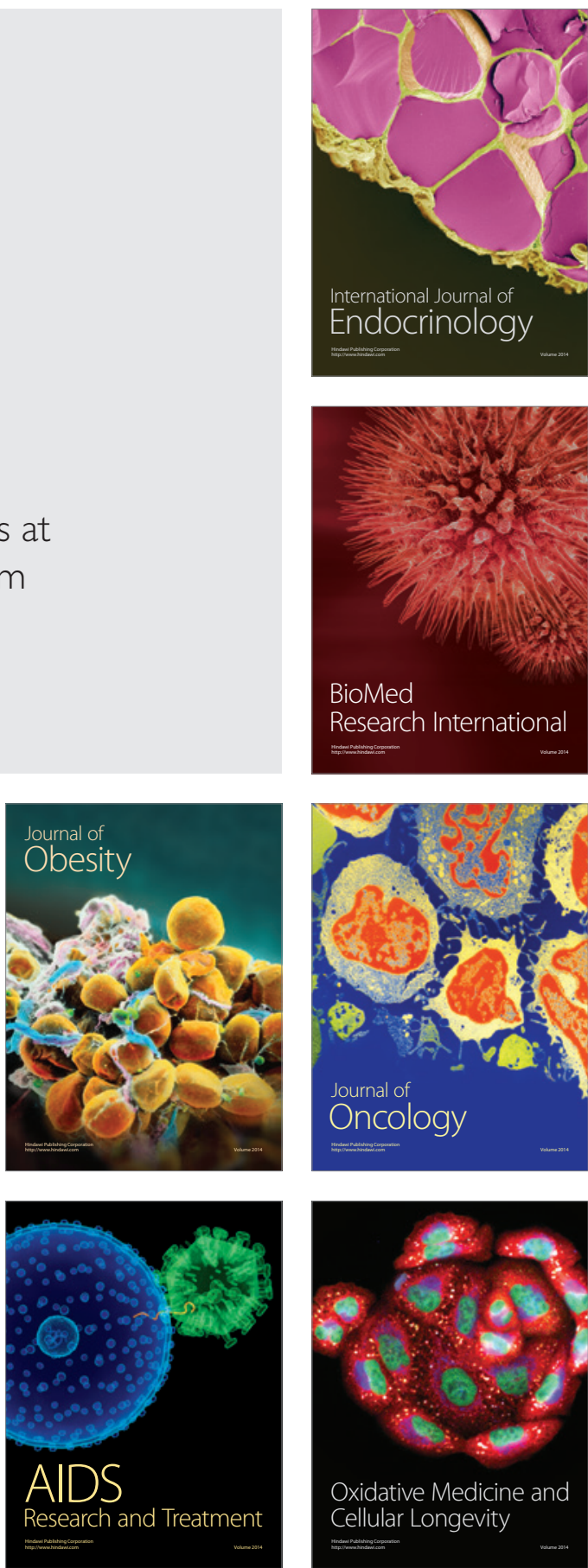